\title{
Positive Expiratory Pressure via Mask Does Not Improve Ventilation Inhomogeneity More than Huffing and Coughing in Individuals with Stable Chronic Obstructive Pulmonary Disease and Chronic Sputum Expectoration
}

\author{
Christian Osadnik $^{\mathrm{a}}$ Christopher Stuart-Andrews ${ }^{\mathrm{b}}$ Samantha Ellis ${ }^{\mathrm{c}}$ \\ Bruce Thompson $^{d}$ Christine F. McDonald ${ }^{e}$ Anne E. Holland ${ }^{f}$ \\ ${ }^{a}$ Department of Physiotherapy, La Trobe University, ${ }^{b}$ Allergy, Immunology and Respiratory Medicine, Alfred Health, \\ 'Department of Radiology, Alfred Health, ${ }^{\mathrm{d}}$ Allergy, Immunology and Respiratory Medicine, Alfred Health/Monash \\ University, ${ }^{e}$ Department of Respiratory and Sleep Medicine, Institute for Breathing and Sleep, Austin Health, and \\ ${ }^{f}$ Department of Physiotherapy, La Trobe University/Alfred Health, Melbourne, Vic., Australia
}

\section{Key Words}

Chronic obstructive pulmonary disease - Ventilation heterogeneity · Airway clearance · Physical therapy modalities · Positive expiratory pressure

\footnotetext{
Abstract

Background: Positive expiratory pressure (PEP) has been used to promote airway clearance in individuals with chronic obstructive pulmonary disease (COPD) for many years; however, its mechanism of action and benefits are unclear. Previous authors have suggested that PEP improves collateral ventilation via changes in lung volumes. Objectives: It was the aim of this study to determine whether PEP improves ventilation inhomogeneity more than controlled huffing and coughing in individuals with stable COPD. Methods: Twelve participants with COPD (mean forced expiratory volume in $1 \mathrm{~s} 45 \%$ predicted) and chronic sputum expectoration performed PEP therapy $\left(10-20 \mathrm{~cm} \mathrm{H}_{2} \mathrm{O}\right)$ or controlled huffing and coughing in random order on alter-
}

nate study days with a 48-hour washout. Measures of acinar and conductive airway ventilation $\left(\mathrm{S}_{\mathrm{acin}}, \mathrm{S}_{\text {cond }}\right)$, lung volumes, spirometry and sputum wet weight were recorded before, immediately after and 90 min following treatment. Ease of expectoration [visual analogue scale (VAS)] and oxyhaemoglobin saturation were assessed immediately following treatment. Results: There were no significant differences between the effect of either test condition at any time point for any test parameter. Mean $\mathrm{S}_{\text {acin }}$ immediately following PEP and control conditions was 0.465 and 0.438 litre $^{-1}$, respectively ( $p=0.45$ for comparison between conditions) and mean $\mathrm{S}_{\text {cond }}$ was 0.042 and 0.039 litre $^{-1}(p=0.55)$. PEP therapy did not significantly enhance total mean sputum expectoration compared to controlled huffing and coughing (7.06 vs. $6.15 \mathrm{~g} ; \mathrm{p}=0.51)$ and did not improve ease of expectoration (VAS PEP $4.8 \mathrm{~cm}$ vs. control $4.1 \mathrm{~cm} ; \mathrm{p}=0.53$ ). Conclusion: Any therapeutic benefits of PEP in individuals with COPD and chronic sputum expectoration are unlikely to be mediated by improvements in ventilation or lung volumes.

Copyright $\odot 2013$ S. Karger AG, Basel

\section{KARGER}

E-Mail karger@karger.com www.karger.com/res
(C) 2013 S. Karger AG, Basel

0025-7931/13/0871-0038\$38.00/0
Christian Osadnik

Department of Physiotherapy

La Trobe University (Alfred Health Clinical School)

Melbourne, VIC 3181 (Australia)

E-Mail crosadnik@students.latrobe.edu.au 


\section{Introduction}

Airway clearance techniques (ACTs) involve the application of external forces and manipulation of lung volumes, pulmonary pressures and gas flow in order to clear sputum from the airways [1]. They are frequently prescribed for patients with chronic obstructive pulmonary disease (COPD) [2,3]. However, convincing evidence of significant clinical benefits is limited [4]. Factors such as disease severity [5], the degree of elastic lung recoil [6] or the presence of other co-existing respiratory conditions such as bronchiectasis [1] (reported in $29-50 \%$ of patients with COPD) $[7,8]$ may influence the response to ACTs.

Positive expiratory pressure (PEP) therapy involves breathing with a slightly active expiration against a mild expiratory resistance (typically $10-20 \mathrm{~cm} \mathrm{H}_{2} \mathrm{O}$ ). It is conventionally performed via a small hand-held mask as part of a cycle that includes huffing and coughing. It has been postulated to assist sputum clearance: by splinting open airways prone to dynamic compression during forced expiratory manoeuvres [9]; reducing gas trapping [10]; improving ventilation and gas flow via recruitment of collateral channels $[11,12]$, possibly due to an increase in functional residual capacity (FRC). Rapid increases in FRC have been demonstrated in adults without respiratory disease [13]; however, the effect of PEP may differ in individuals with COPD where FRC can be significantly elevated. For example, in healthy lungs, there is typically a uniform (homogenous) distribution of ventilation, due to equal rates of filling and emptying of individual lung units. In COPD, ventilation is often non-uniform (inhomogenous) due to asynchronous filling and emptying of lung units.

Ventilation inhomogeneity can be quantified from multiple-breath nitrogen washout (MBNW) tests. The lung clearance index (LCI) is a global measure of ventilation inhomogeneity in both the small and large airways and is calculated as the number of lung turnovers (cumulative expired volume divided by FRC) required to reduce end-tidal nitrogen concentration to below a fixed value. This is usually $2 \%$ absolute or $1 / 40$ th of the starting nitrogen concentration [14, 15]; however, differing end-tidal values such as $5 \%$ or $1 / 20$ th of the starting nitrogen concentration have also been used [16]. Ventilation inhomogeneity can be further partitioned into two distinct distal airway regions based on different modes of gas transport (convection and diffusion) within the lung [17]. Ventilation inhomogeneity due to uneven distribution of convective gas flow is termed ' $\mathrm{S}_{\text {cond }}$ ' whilst the interaction between diffusive and convective gas flow, occurring at the acinar entrance, is assessed by the index $S_{\text {acin. }}$ Elevation of both these indices has been shown to correlate to the worsening of ventilation inhomogeneity [18].

Evaluation of the effect of ACTs using measures of ventilation distribution offers considerable advantage over widely used spirometric outcomes as the sensitivity to detect change, particularly in the small airways (the 'quiet zone') [19], is significantly enhanced [17, 18, 20, 21 . Despite this, the use of such procedures in ACT studies is rare. In a study by Darbee et al. [22], 5 children with cystic fibrosis demonstrated that measurements of ventilation distribution via a single-breath helium dilution technique worsened following PEP mask therapy whilst small improvements in the forced expiratory volume in $1 \mathrm{~s}\left(\mathrm{FEV}_{1}\right)$ were detected. However, this study did not standardize the frequency of coughing and huffing across both test conditions despite their known influence on sputum clearance $[6,23,24]$. Controlling for this effect is crucial in order for the effect of PEP to be isolated.

Aim

The principal aim of the study was to identify whether PEP mask therapy improves ventilation inhomogeneity $\left(\mathrm{S}_{\text {acin }}, \mathrm{S}_{\text {cond }}\right)$ and increases FRC compared to controlled huffing and coughing in individuals with stable COPD and chronic sputum expectoration. The influence of disease severity, co-existing bronchiectasis and the amount of sputum expectorated on PEP mask therapy effectiveness was also explored.

\section{Material and Methods}

\section{Ethics}

This study was approved by the Human Ethics Committees of Alfred Health (359/09) and La Trobe University (09-060).

\section{Participants}

Individuals with at least moderate [25], stable COPD (no history of an exacerbation requiring medical treatment for the previous 4 weeks) [26] and usual sputum expectoration ('regular expectoration of sputum on most days') were recruited from a tertiary hospital in Melbourne, Australia, between April 2010 and October 2011. Individuals were ineligible if they had severe or widespread bullous disease affecting $>50 \%$ of any lobe, a history of recent ( $<6$ months) pneumothorax or resting oxyhaemoglobin saturation $\left(\mathrm{SpO}_{2}\right)<90 \%$ on room air [21] or were unable to provide informed consent.

Study Design

This was a randomized crossover trial comparing the effect of 15 min of PEP mask therapy to 15 min of controlled huffing and coughing (fig. 1). The primary outcomes were $S_{\text {acin }}$ and $S_{\text {cond }}$, and the secondary outcomes were FRC, residual volume (RV), total lung capacity (TLC), RV/TLC, inspiratory capacity (IC), $\mathrm{FEV}_{1}$, 
Fig. 1. Study design.

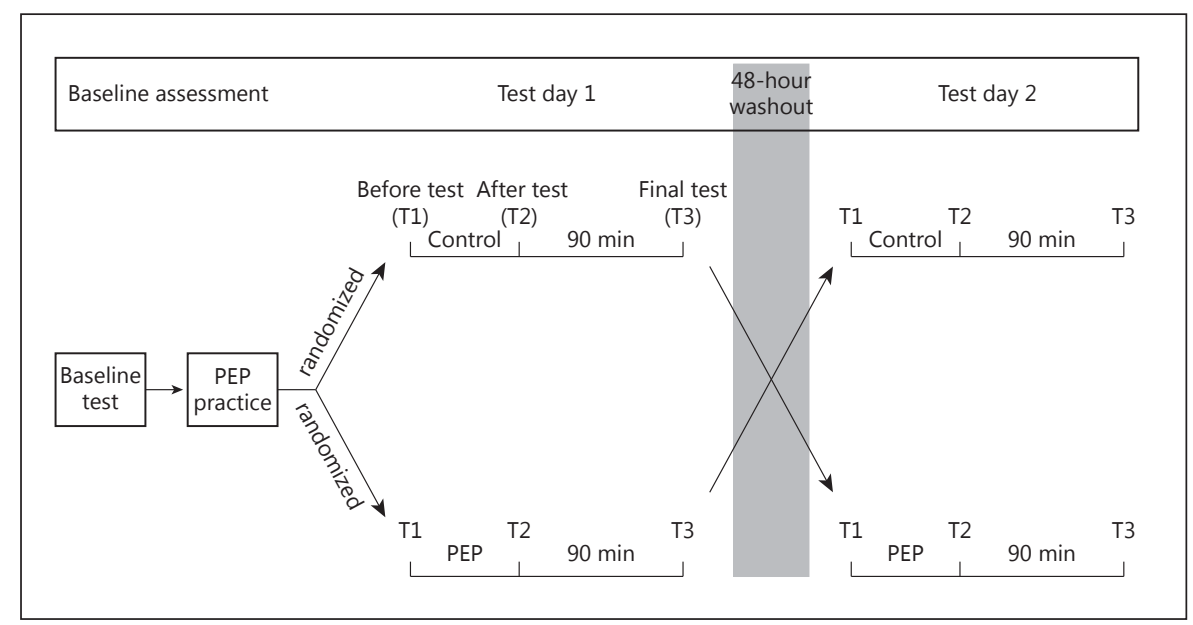

forced vital capacity (FVC), $\mathrm{FEV}_{1} / \mathrm{FVC}$, LCI at 5 and $2 \%, \mathrm{SpO}_{2}$, sputum wet weight and self-reported ease of expectoration.

\section{Test Protocol}

The baseline assessment comprised pre- and post-bronchodilator spirometry, gas transfer factor and a high-resolution computed tomography of the chest to identify significant bullous disease (sharply demarcated areas of emphysema of $\geq 1 \mathrm{~cm}$ diameter possessing a thin epithelialized wall of $\leq 1 \mathrm{~mm}$ ) and/or co-existing bronchiectasis [localized irreversible bronchial dilatation as identified by a bronchoarterial ratio (internal bronchial diameter/accompanying artery diameter) $>1$, a visible airway within $1 \mathrm{~cm}$ of the costal pleural surface, or direct contact of an airway with the mediastinal pleural surface]. Modified Bhalla criteria $[27,28]$ were used to quantify the degree of bronchiectasis as a score from 0 to 54 (the higher the score, the more severe the disease), with total extent scores $\geq 2$ deemed clinically significant [8]. Further details are provided in the online supplementary material (for all online suppl. material, see www.karger.com/doi/10.1159/000348546).

Participants then performed a control or PEP mask intervention (order randomized) at the same time of day on 2 study days, with at least 48-hour washout between visits. Tests of lung function (MBNW, spirometry and lung volumes, in order) were performed before (T1), immediately after (T2) and 90 min following treatment (T3) (fig. 1). Participants took their usual respiratory medications but were administered bronchodilator therapy $(300 \mu \mathrm{g}$ salbutamol via metered dose inhaler with spacer) prior to baseline testing to enhance standardization. Block randomization was performed via a web-based sequence generator, and treatment order (group allocation) was concealed using sealed, sequentially numbered opaque envelopes.

\section{Experimental Conditions}

Control

Participants sat in an upright position and breathed normally for $15 \mathrm{~min}$. At 3-min intervals, they performed two huffs through standard mouthpiece tubing. The first was from a low lung volume (small inspiration, prolonged expiration) and the second from a mid-lung volume (moderate inspiration, moderate expiration). This was followed by two strong coughs (five cycles total).

\section{Intervention}

Participants sat in a forward lean position with elbows rested on a table and held a PEP mask (Astra-tech $\mathrm{AB}^{\odot}$ ) over the nose and mouth to create an airtight seal. A valve on the front directed inspiration through a one-way inlet and expiration through a oneway outlet connected to a small expiratory resistor (internal diameter range $1.5-5.0 \mathrm{~mm}$ ). Participants took 10 tidal volume breaths with a slightly active expiration to achieve a stable expiratory pressure of $10-20 \mathrm{~cm} \mathrm{H}_{2} \mathrm{O}$ [29] (monitored via a pressure manometer), followed by two huffs through standard mouthpiece tubing and two strong coughs. This cycle was repeated five times over a 15min period.

\section{Outcomes and Equipment}

MBNW testing was performed using a double 'bag-in-box' system with participants seated upright and instructed to breathe at 1 litre tidal volumes (visual assistance provided via a computer display). Following a period of stable air breath, participants were switched to breathing of $100 \% \mathrm{O}_{2}$. Nitrogen concentration was continuously monitored at the mouth (AU9240-4032, Medical Graphics Corporation, St. Paul, Minn., USA) while flow and volume were calculated by volume displacement from within the double bag-in-box system and measured by pneumotachography (Fleish type, flow range $0-5$ litres $\cdot \mathrm{s}^{-1}$ ). Participants continued to breathe $\mathrm{O}_{2}$ until nitrogen was washed out to below 2\%. This test was repeated three times at each time point (total $9 \mathrm{MBNW} /$ day), with sufficient time allowed for complete re-equilibration of nitrogen within the lung FRC before subsequent testing was commenced [30]. Further details of the equipment set-up and test protocol are described by Stuart-Andrews et al. [31].

Analysis of the MBNW tests was undertaken using a previously described automated technique, whereby the slope of the alveolar (or phase III) portion of each breath recorded during the washout was calculated [31]. Indices of ventilation inhomogeneity $\left(S_{\text {acin }}\right.$ and $\mathrm{S}_{\text {cond }}$ ) were determined and interpreted as described by Verbanck et al. [17, 32], and LCI was calculated as previously described [14-16]. Spirometry and lung volumes (via constant volume body plethysmography) were performed using standard lung function equipment (Platinum Elite series, Medical Graphics Corporation) interfaced with MedGraphics Breeze software in accordance with 
American Thoracic Society/European Respiratory Society guidelines $[33,34]$.

Oxyhaemoglobin saturation was measured using a portable pulse oximeter (Massimo, Radical 7) and digital probe before and immediately after treatment. Sputum wet weight (g) was recorded using a calibrated digital weighing scale before and after lung function testing. Participants rated their ease of sputum expectoration immediately after treatment using a $10-\mathrm{cm}$ visual analogue scale (VAS; 0 = extremely easy; $10=$ extremely difficult) which asked 'how easy was it to cough and expectorate sputum?'

\section{Blinding}

The assessors responsible for conducting and analysing the MBNWs (C.S.-A.) and chest high-resolution computed tomographies (S.E.) were blind to the participants' treatment order throughout the study. The outcome assessor responsible for collecting and analysing all other secondary outcomes was the treating therapist (C.O.) who was not blind to group allocation.

\section{Statistical Analysis}

The effect of the test conditions on ventilation inhomogeneity $\left(\mathrm{S}_{\text {cond }}, \mathrm{S}_{\mathrm{acin}}, \mathrm{LCI} 5 \%, \mathrm{LCI} \%\right)$ and lung function (FRC, TLC, RV, $\mathrm{RV} / \mathrm{TLC}, \mathrm{IC}, \mathrm{FEV}_{1}, \mathrm{FVC}$ ) at T2 and T3 was analysed using separate linear mixed-model analyses for each outcome. Each model comprised allocation sequence, test day and test condition as fixed effects and participants as random effects. A sensitivity analysis was performed to investigate the effect of incorporating baseline data (T1) as a fixed effect covariate in the model for the primary outcomes. Paired t tests (two-tailed) were used to compare the effect of treatment on $\mathrm{SpO}_{2}$, sputum wet weight and VAS scores. The effect of disease severity, co-existing bronchiectasis and sputum production on $\mathrm{S}_{\text {acin }}$ and $\mathrm{S}_{\text {cond }}$ were explored via correlation co-efficients. Cronbach's a was set at 0.05 . P values less than 0.05 were considered statistically significant.

\section{Results}

Ninety-three individuals with COPD were screened for study eligibility. Most were excluded due to not regularly expectorating sputum $(40 / 93,43 \%)$. Thirteen participants were recruited and randomized (6 PEP first); however 1 subject [male, 71 years old, $\mathrm{FEV}_{1} 0.95$ litre (33.5\% predicted)] did not return after the first study day (PEP) and was excluded from all analyses. Another could not perform acceptable manoeuvres for calculation of lung volumes and was excluded from analysis of these data only. Key demographic data for the 12 participants are presented in table 1. Data from the quantitative analysis are presented in table 2. Further individual data are available in the online supplementary material.

\section{Primary Outcomes}

There were no statistically significant within-group changes or between-group differences in $\mathrm{S}_{\text {acin }}$ or $\mathrm{S}_{\text {cond }}$ at
Table 1. Baseline characteristics of participants

\begin{tabular}{|c|c|}
\hline Participant characteristics & $\mathrm{n}=12$ \\
\hline Age, years & $66.1 \pm 8.6$ \\
\hline Gender, male:female & $8: 4$ \\
\hline Body mass index & $27.1 \pm 3.9$ \\
\hline Smoking status, current:former & $2: 10$ \\
\hline Smoking, pack-years & $67.4 \pm 60.9$ \\
\hline Previously diagnosed respiratory comorbidity & $5(42)$ \\
\hline Radiological evidence of significant bronchiectasis & $8(66.7)$ \\
\hline \multicolumn{2}{|l|}{ Self-reported usual daily sputum expectoration } \\
\hline$\leq 1$ teaspoon & $2(17)$ \\
\hline $1-3$ tablespoons & $7(58)$ \\
\hline$\geq 1 / 2$ cup & $3(25)$ \\
\hline \multicolumn{2}{|l|}{ Post-bronchodilator lung function } \\
\hline $\mathrm{FEV}_{1}$, litre & $1.3 \pm 0.5$ \\
\hline $\mathrm{FEV}_{1}, \%$ predicted & $45.2 \pm 18.5$ \\
\hline FVC, litre & $3.4 \pm 0.8$ \\
\hline FVC, \% predicted & $85.9 \pm 17.1$ \\
\hline $\mathrm{FEV}_{1} / \mathrm{FVC}$ & $0.38 \pm 0.12$ \\
\hline $\mathrm{T}_{\mathrm{L}} \mathrm{CO}_{\mathrm{Hb}}, \%$ predicted & $51.1 \pm 19.2$ \\
\hline FRC, litre ${ }^{\text {a }}$ & $4.87 \pm 1.08$ \\
\hline FRC, \% predicted & $139 \pm 22$ \\
\hline $\mathrm{RV}$, litre ${ }^{\mathrm{a}}$ & $3.59 \pm 0.99$ \\
\hline RV, \% predicted & $158 \pm 40$ \\
\hline TLC, litre ${ }^{\mathrm{a}}$ & $7.36 \pm 1.36$ \\
\hline TLC, \% predicted & $124 \pm 13$ \\
\hline $\mathrm{RV}^{\mathrm{TLC}} \mathrm{C}^{\mathrm{a}}$ & $48.7 \pm 8.6$ \\
\hline IC, litre ${ }^{\mathrm{a}}$ & $2.43 \pm 0.62$ \\
\hline$S_{\text {acin }}$, litre $^{-1}$ & $0.498 \pm 0.11$ \\
\hline $\mathrm{S}_{\mathrm{acin}}, \%$ predicted & $426 \pm 88$ \\
\hline $\mathrm{S}_{\text {cond }}$, litre ${ }^{-1}$ & $0.041 \pm 0.02$ \\
\hline $\mathrm{S}_{\text {cond }}, \%$ predicted & $97 \pm 53$ \\
\hline GOLD stage, 1:2:3:4 & $0: 5: 4: 3$ \\
\hline
\end{tabular}

Data are the mean $\pm S D$, or the number of patients, with percentages in parentheses. $\mathrm{T}_{\mathrm{L}} \mathrm{CO}_{\mathrm{Hb}}=$ Transfer factor of carbon monoxide adjusted for haemoglobin; GOLD = Global Initiative for Chronic Obstructive Lung Disease.

${ }^{\mathrm{a}}$ Measured on 11 participants only.

any time point (fig. 2,3). Results from the sensitivity analysis did not differ. No statistically significant correlations with disease severity, extent of co-existing bronchiectasis or sputum wet weight existed.

\section{Secondary Outcomes}

No statistically different between-group differences in LCI2\% or LCI5\% existed at T2 or T3. Despite very small within-group increases in FRC following both test conditions (fig. 4), no statistically significant differences were evident between test conditions at T2 or T3 for FRC or any other lung volume or spirometric parameter. A nonsignificant trend towards greater improvement in $\mathrm{FEV}_{1}$ following PEP compared to controlled coughing was observed ( 42 vs. $5 \mathrm{ml}$ ). 
Table 2. Results of linear mixed-model analysis

\begin{tabular}{|c|c|c|c|c|c|c|c|c|c|c|}
\hline & \multicolumn{5}{|l|}{$\mathrm{T} 2$} & \multicolumn{5}{|l|}{ T3 } \\
\hline & $\begin{array}{l}\text { mean PEP - } \\
\text { control }\end{array}$ & lower CI & upper CI & PEP & control & $\begin{array}{l}\text { mean PEP - } \\
\text { control }\end{array}$ & lower CI & upper CI & PEP & control \\
\hline$S_{\text {acin }}$, litre $^{-1}$ & 0.026 & -0.048 & 0.101 & 0.465 & 0.438 & 0.001 & -0.069 & 0.070 & 0.453 & 0.452 \\
\hline LCI2\% (TO) & 0.024 & -0.648 & 0.695 & 13.450 & 13.427 & 0.144 & -0.536 & 0.247 & 13.093 & 13.237 \\
\hline FRC, litre & -0.06 & -0.21 & 0.09 & 5.07 & 5.13 & 0.02 & -0.20 & 0.25 & 5.14 & 5.12 \\
\hline RV, litre & -0.02 & -0.20 & 0.17 & 3.74 & 3.76 & 0.09 & -0.07 & 0.25 & 3.84 & 3.75 \\
\hline TLC, litre & -0.08 & -0.21 & 0.03 & 7.55 & 7.63 & 0.04 & -0.20 & 0.29 & 7.63 & 7.59 \\
\hline RV/TLC & 0.00 & -0.02 & 0.02 & 0.49 & 0.49 & 0.01 & -0.01 & 0.03 & 0.50 & 0.49 \\
\hline IC, litre & -0.03 & -0.23 & 0.18 & 2.40 & 2.43 & 0.02 & -0.32 & 0.34 & 2.40 & 2.38 \\
\hline
\end{tabular}

Data are the mean difference between treatments immediately after (T2) and 90 min following treatment (T3), and least square mean values for PEP and control conditions at T2 and T3. CI = Confidence interval; TO = turnovers (cumulative expired volume divided by FRC).

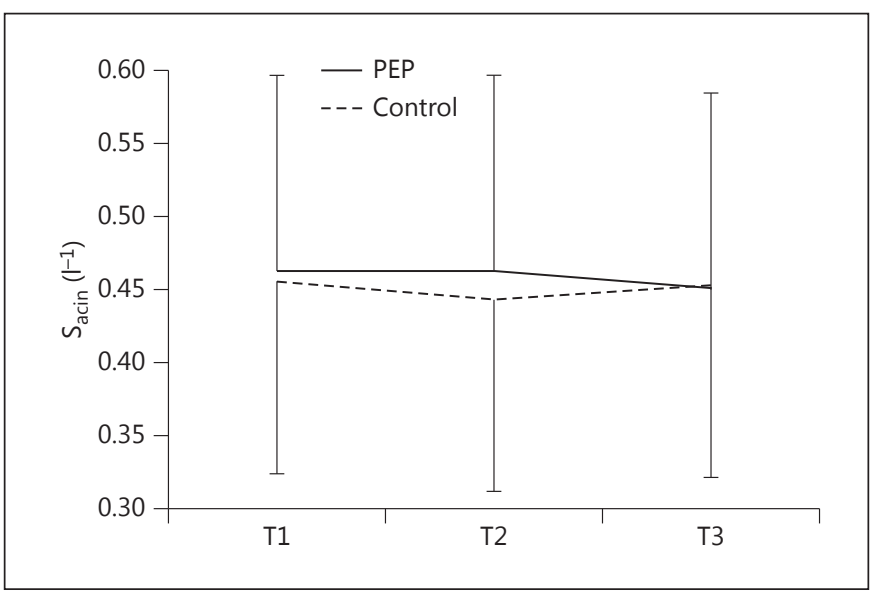

Fig. 2. Mean (standard error) $S_{a c i n}$ over time. $T 1=$ Before treatment; T2 = immediately after treatment; T3 = 90 min following treatment.

Complete pre- and post-treatment $\mathrm{SpO}_{2}$ data from both test conditions were obtained from 9 participants only. Mean (SD) end-treatment $\mathrm{SpO}_{2}$ was $93.6 \%$ (1.7) and 93.7\% (2.5) following PEP and control, respectively ( $\mathrm{p}=$ $0.84)$. Mean (SD) sputum wet weight immediately following treatment was $3.87 \mathrm{~g} \mathrm{(4.7)} \mathrm{(PEP)} \mathrm{and} 3.77 \mathrm{~g} \mathrm{(4.3)} \mathrm{(con-}$ trol), increasing to $7.06 \mathrm{~g}$ (7.9) (PEP) and $6.15 \mathrm{~g}(6.1)$

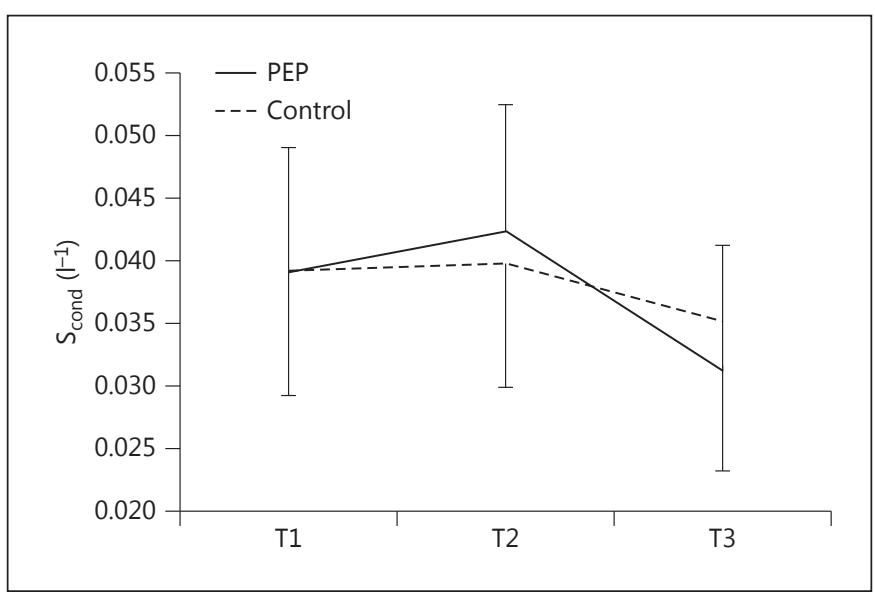

Fig. 3. Mean (standard error) $\mathrm{S}_{\text {cond }}$ over time. $\mathrm{T} 1=$ Before treatment; $\mathrm{T} 2$ = immediately after treatment; $\mathrm{T} 3=90 \mathrm{~min}$ following treatment.

(control) by the end of T3 $(\mathrm{p}=0.51)$. VAS scores were not significantly different ( $4.8 \mathrm{~cm}$ PEP vs. $4.1 \mathrm{~cm}$ control; $\mathrm{p}=$ $0.53)$. No adverse events occurred throughout the study. Data of individual participants are available in the online supplementary material.
42 


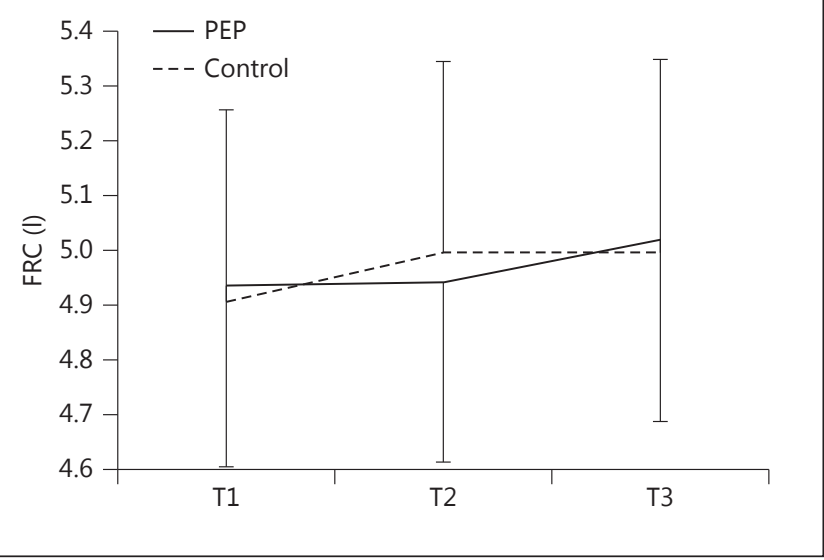

Fig. 4. Mean (standard error) FRC over time. T1 = Before treatment; T2 = immediately after treatment; $\mathrm{T} 3=90 \mathrm{~min}$ following treatment.

\section{Discussion}

This was the first study to investigate the effect of PEP on ventilation inhomogeneity and FRC in individuals with COPD and regular sputum expectoration. No clinically or statistically significant differences were found for any measure of ventilation or lung function between the two test conditions. The lack of change in $\mathrm{S}_{\text {acin }}, \mathrm{S}_{\text {cond }}, \mathrm{FRC}$ and RV/TLC fails to support two of the three mechanisms proposed to explain how PEP benefits sputum clearance, namely improvement in pulmonary ventilation and gas flow and a reduction in gas trapping. The ability of PEP to create a protective splinting effect during active expirations was not directly examined in the present study; however, no anticipated reduction in RV was observed. This raises questions regarding the effectiveness and rationale for using PEP in this patient group.

The primary outcomes used in this study $\left(\mathrm{S}_{\text {acin }}, \mathrm{S}_{\text {cond }}\right)$ have typically been utilized to characterize lung disease severity and progression $[17,18,35,36]$ due to their capability to detect subtle change in the structure and function of the small airways. Their limited use in studies of ACTs means comparison of our findings to existing literature is not possible. One PEP session may have been insufficient to alter small airway structure; however, the absence of change in small airway function was likely due to a true absence of effect given the high sensitivity of these parameters [37]. The novel application of MBNW technology in this study was warranted by the specific physiological aims and proved both feasible and well tolerated by participants.

PEP Does Not Improve Ventilation Inhomogeneity in COPD
Mean sputum expectoration was generally low throughout this study and did not significantly correlate with the extent of bronchiectasis or the severity of COPD. The importance of the within-group changes in sputum wet weight from baseline were difficult to ascertain as no minimally important difference exists in clinical practice, and comparisons between conditions were confounded by the effect of repeated forced expiratory manoeuvres during serial lung function tests. This may have contributed to the lack of observed benefit of PEP on sputum expectoration and contrasts the notion that ACTs may be more important in 'wet' versus 'dry' COPD phenotypes.

The findings of this study are consistent with previous literature in stable COPD that reported endpoints including $\mathrm{FEV}_{1}[38,39], \mathrm{RV}[40]$ and $\mathrm{SpO}_{2}$ [41]. Whether the MBNW findings have implications for individuals with acute exacerbations of COPD, where ACTs appear to differ in their effects compared to stable disease [4] and are more frequently prescribed $[2,3]$, remains unclear. Replicating this study in an acute environment would be challenging as the washout duration is likely to coincide with significant clinical improvement, and tolerance to repeated lung function tests may be low. The use of MBNW tests as a sole outcome is limited by its present lack of accuracy to measure changes in lung volumes, particularly FRC.

Results from this study indicate that a single PEP mask treatment does not improve ventilation inhomogeneity or increase FRC more than huffing and coughing in individuals with COPD and regular sputum expectoration. Therefore, any benefits derived from PEP therapy in this patient group do not appear to be mediated by improvements in ventilation due to changes in lung volumes.

\section{Acknowledgements}

The authors would like to thank the staff at the Alfred Health lung function laboratory for their assistance coordinating this study, Sylvia Verbanck for her contribution towards the project direction and data interpretation and Steve Vander Hoorn for essential statistical assistance.

\section{Financial Disclosure and Conflicts of Interest}

None of the authors has a conflict of interest related to the content of the manuscript. 


\section{References}

$>1$ Holland AE, Button BM: Is there a role for airway clearance techniques in chronic obstructive pulmonary disease? Chron Respir Dis 2006;3:83-91.

-2 Osadnik CR, McDonald CF, Holland AE: Airway clearance techniques in acute exacerbations of chronic obstructive pulmonary disease: a survey of Australian physiotherapists. Physiotherapy 2013;99:101-106.

3 Lee A, Button B, Denehy L: Current Australian and New Zealand physiotherapy practice in the management of patients with bronchiectasis and chronic obstructive pulmonary disease. NZ J Physiother 2008;36:49-58.

4 Osadnik CR, McDonald CF, Jones AP, Holland AE: Airway clearance techniques for chronic obstructive pulmonary disease. Cochrane Database Syst Rev 2012;3:CD008328.

$\checkmark 5$ Marini JJ, Tyler ML, Hudson LD, Davis BS Huseby JS: Influence of head-dependent positions on lung volume and oxygen saturation in chronic air-flow obstruction. Am Rev Respir Dis 1984;129:101-105.

-6 Van der Schans CP, Piers DA, Beekhuis H, Koeter GH, Van der Mark TW, Postma DS: Effect of forced expirations on mucus clearance in patients with chronic airflow obstruction: effect of lung recoil pressure. Thorax 1990;45:623-627.

7 O'Brien C, Guest PJ, Hill SL, Stockley RA: Physiological and radiological characterisation of patients diagnosed with chronic obstructive pulmonary disease in primary care. Thorax 2000;55:635-642.

8 Patel IS, Vlahos I, Wilkinson TM, LloydOwen SJ, Donaldson GC, Wilks M, Reznek RH, Wedzicha JA: Bronchiectasis, exacerbation indices, and inflammation in chronic obstructive pulmonary disease. Am J Respir Crit Care Med 2004;170:400-407.

9 Oberwaldner B, Evans JC, Zach MS: Forced expirations against a variable resistance: a new chest physiotherapy method in cystic fibrosis. Pediatr Pulmonol 1986;2:358-367.

10 Fagevik Olsen M, Westerdahl E: Positive expiratory pressure in patients with chronic obstructive pulmonary disease - a systematic review. Respiration 2009;77:110-118.

$>11$ Andersen JB, Qvist J, Kann T: Recruiting collapsed lung through collateral channels with positive end-expiratory pressure. Scand J Respir Dis 1979;60:260-266.

12 Groth S, Stafanger G, Dirksen H, Andersen JB, Falk M, Kelstrup M: Positive expiratory pressure (PEP-mask) physiotherapy improves ventilation and reduces volume of trapped gas in cystic fibrosis. Bull Eur Physiopathol Respir 1985;21:339-343.

$\checkmark 13$ Garrard CS, Shah M: The effects of expiratory positive airway pressure on functional residual capacity in normal subjects. Crit Care Med 1978;6:320-322.

$>14$ Bouhuys A: Pulmonary nitrogen clearance in relation to age in healthy males. J Appl Physiol 1963;18:297-300.
15 Cumming G, Jones JG: The construction and repeatability of lung nitrogen clearance curves. Respir Physiol 1966;1:238-248.

16 Becklake MR: A new index of the intrapulmonary mixture of inspired air. Thorax 1952;7: $111-116$.

17 Verbanck S, Schuermans D, Van Muylem A, Paiva M, Noppen M, Vincken W: Ventilation distribution during histamine provocation. J Appl Physiol 1997;83:1907-1916.

18 Verbanck S, Schuermans D, Meysman M, Paiva M, Vincken W: Noninvasive assessment of airway alterations in smokers: the small airways revisited. Am J Respir Crit Care Med 2004;170:414-419.

19 Usmani OS: Unravelling the small airways: structure-function-treatment relationships in asthma and COPD. Respiration 2012;84:1-3.

20 Cosio MG: Looking at the acinus with function tests: can you believe it? Am J Respir Crit Care Med 2006;174:847-848.

21 Verbanck S, Schuermans D, Vincken W: Small airways ventilation heterogeneity and hyperinflation in COPD: response to tiotropium bromide. Int J Chron Obstruct Pulmon Dis 2007;2:625-634.

22 Darbee JC, Ohtake PJ, Grant BJ, Cerny FJ: Physiologic evidence for the efficacy of positive expiratory pressure as an airway clearance technique in patients with cystic fibrosis. Phys Ther 2004;84:524-537.

23 Hasani A, Pavia D, Agnew JE, Clarke SW: Regional lung clearance during cough and forced expiration technique (FET): effects of flow and viscoelasticity. Thorax 1994;49:557561.

24 Hasani A, Pavia D, Agnew JE, Clarke SW: Regional mucus transport following unproductive cough and forced expiration technique in patients with airways obstruction. Chest 1994;105:1420-1425.

25 Global Initiative for Chronic Obstructive Lung Disease (GOLD): Global strategy for the diagnosis, management and prevention of COPD (revised 2011). http://www.goldcopd. org/.

26 Burgel PR, Nesme-Meyer P, Chanez P, Caillaud D, Carre P, Perez T, Roche N: Cough and sputum production are associated with frequent exacerbations and hospitalizations in COPD subjects. Chest 2009;135:975-982.

27 Bhalla M, Turcios N, Aponte V, Jenkins M, Leitman BS, McCauley DI, Naidich DP: Cystic fibrosis: scoring system with thin-section CT. Radiology 1991;179:783-788.

28 Roberts HR, Wells AU, Milne DG, Rubens MB, Kolbe J, Cole PJ, Hansell DM: Airflow obstruction in bronchiectasis: correlation between computed tomography features and pulmonary function tests. Thorax 2000;55: 198-204.

29 Falk M, Kelstrup M, Andersen JB, Kinoshita T, Falk P, Stovring S, Gothgen I: Improving the ketchup bottle method with positive expiratory pressure, PEP, in cystic fibrosis. Eur J Respir Dis 1984;65:423-432.
30 Salamon E, Gain K, Hall G: Multibreath nitrogen washout: how long must we wait? Australia and New Zealand Society of Respiratory Science, Perth, Australia. Respirology 2010; 15:A2.

-31 Stuart-Andrews CR, Kelly VJ, Sands SA, Lewis AJ, Ellis MJ, Thompson BR: Automated detection of the phase III slope during inert gas washout testing. J Appl Physiol 2012;112: 1073-1081.

32 Verbanck S, Thompson BR, Schuermans D, Kalsi H, Biddiscombe M, Stuart-Andrews C, Hanon S, Van Muylem A, Paiva M, Vincken $\mathrm{W}$, Usmani O: Ventilation heterogeneity in the acinar and conductive zones of the normal ageing lung. Thorax 2012;67:789-795.

33 Miller MR, Hankinson J, Brusasco V, Burgos F, Casaburi R, Coates A, Crapo R, Enright P, Van der Grinten CP, Gustafsson P, Jensen R, Johnson DC, MacIntyre N, McKay R, Navajas D, Pedersen OF, Pellegrino R, Viegi G, Wanger J: Standardisation of spirometry. Eur Respir J 2005;26:319-338.

34 Wanger J, Clausen JL, Coates A, Pedersen OF, Brusasco V, Burgos F, Casaburi R, Crapo R, Enright P, van der Grinten CP, Gustafsson P, Hankinson J, Jensen R, Johnson D, Macintyre N, McKay R, Miller MR, Navajas D, Pellegrino R, Viegi G: Standardisation of the measurement of lung volumes. Eur Respir J 2005; 26:511-522.

35 Verbanck S, Schuermans D, Noppen M, Van Muylem A, Paiva M, Vincken W: Evidence of acinar airway involvement in asthma. Am J Respir Crit Care Med 1999;159:1545-1550.

36 Verbanck S, Schuermans D, Van Muylem A, Melot C, Noppen M, Vincken W, Paiva M: Conductive and acinar lung-zone contributions to ventilation inhomogeneity in COPD. Am J Respir Crit Care Med 1998;157:15731577.

37 Verbanck S: Physiological measurement of the small airways. Respiration 2012;84:177188 .

38 Van Hengstum M, Festen J, Beurskens C, Hankel M, van den Broek W, Buijs W, Corstens F: The effect of positive expiratory pressure versus forced expiration technique on tracheobronchial clearance in chronic bronchitics. Scand J Gastroenterol Suppl 1988;143: 114-118.

39 Christensen EF, Norregaard O, Dahl R: Nebulized terbutaline and positive expiratory pressure in chronic obstructive pulmonary disease. Pneumologie 1991;45:105-109.

40 Cegla UH, Jost JH, Harten A, Weber T: RCCornet improves the bronchodilating effect of ipratropiumbromide (Atrovent) inhalation in COPD-patients. Pneumologie 2001;55:465469.

41 Wolkove N, Kamel H, Rotaple M, Baltzan MA Jr: Use of a mucus clearance device enhances the bronchodilator response in patients with stable COPD. Chest 2002;121:702-707. 